\title{
Encontros Terapêuticos: Tecnologias Populares no Tratamento do Câncer de Colo de Utero
}

\author{
Oliveira, Pricilla Emanuelly de; Guimarães, Sílvia Maria Ferreira \\ Universidade de Braília - pricilla.emanuelly@hotmail.com
}

\begin{abstract}
Introdução no Centro de Alta Complexidade em Oncologia (CACON) do Hospital Universitário de Brasília (HUB) as pacientes com câncer de colo de útero vivenciam procedimentos terapêuticos marcados pelo uso de tecnologias como a quimioterapia e a braquiterapia. Diante desse processo, há uma transformação na maneira como essas mulheres passam a perceber as seus corpos, elaboram novas formas de vivenciar os procedimentos terapêuticos e se reconstituírem como sujeitos. Essa dinâmica transformacional está pautada por encontros na sala de espera que acabam por se tornarem momentos de sociabilidade terapêuticos, o qual será tema deste trabalho. Objetivos Discutir a compreensão e visão das pacientes com câncer de colo de útero sobre o processo de adoecimento e os procedimentos terapêuticos disponibilizados no CACON do HUB. Analisar o discurso das pacientes sobre o câncer e as tecnologias empregadas no tratamento. Apresentar conclusões sobre o relacionamento médico-paciente e a relação das pacientes com outros profissionais de saúde envolvidos no tratamento da doença e entre elas. Metodologia: a metodologia utilizada na pesquisa foi a etnografia, com base em anotações dos principais pontos comentados pelas pacientes e utilização de um diário de campo para anotações de vários outros fatos que ocorreram no ambiente de pesquisa, assim como as impressões pessoais da pesquisadora. a fase de coleta dados foi realizada entre os meses de fevereiro e maio de 2012, junto a duas pacientes em tratamento no CACON e dois profissionais de saúde. Resultados: do diagnóstico ao tratamento do câncer de colo de útero, a paciente vai do ataque ao contra-ataque, adentrando em uma "guerra" onde espera sofrer efeitos desconhecidos e que supõe serem avassaladores sobre seu corpo, fazendo-o viver rupturas radicais na sua vida. As pacientes se encontram fragilizadas e ansiosas, sendo que no decorrer do tratamento a condição de fragilidade se potencializa, demandando atenção especial da equipe multiprofissional. Olhar para as tecnologias, corpo biológico e cura e, não para a pessoa em sua singularidade, leva a problemas de adesão ao tratamento, angústia e incompreensão. Diante de tal processo, na sala de espera do HUB ou salinha como elas se referem, surgem momentos quando são compartilhadas experiências e maneiras de aliviar o tratamento. Assim, essas mulheres se elevam sobre os estigmas que the são impostos pela sociedade e área médica para lidar com tal enfermidade com autonomia e controle sobre os procedimentos. Conclusão: o conhecimento de si adquirido a partir das discussões e conversas realizadas entre as mulheres nas salas de espera do CACON demonstram a fixação da identidade dessas mulheres portadoras de câncer de colo de útero em função da busca da cura e do apoio na religião, em amigos e familiares, e umas nas outras por meio de trocas de experiências.
\end{abstract}

Oliveira, Pricilla Emanuelly de; Guimarães, Sílvia Maria Ferreira. Encontros Terapêuticos: Tecnologias Populares no Tratamento do Câncer de Colo de Útero. In: Anais do Congresso Internacional de Humanidades \& Humanização em Saúde [= Blucher Medical Proceedings, num.2, vol.1]. São Paulo: Editora Blucher, 2014. ISSN 2357-7282 DOI 10.5151/medpro-cihhs-10580 